\title{
PROPRIEDADES FÍSICAS E QUIMMICAS DE FEIJÃO COMUM PRETO, CULTIVAR IAPAR 44, APÓS ENVELHECIMENTO ACELERADO ${ }^{1}$
}

\author{
Horaci Jaqueline Silva de Souza RIBEIRO², Sandra Helena PRUDENCIO-FERREIRA2,*,
}

Dalva Tomoe MIYAGUI ${ }^{3}$

\begin{abstract}
RESUMO
Feijão armazenado por período longo em temperatura e umidade relativa elevadas torna-se endurecido e resistente ao cozimento devido ao desenvolvimento do defeito "dificil de cozinhar". Este trabalho teve como objetivo avaliar algumas propriedades fisicas e quimicas de feijão comum preto (Phaseolus vulgaris L.) cultivar Iapar 44, envelhecido. O envelhecimento do feijão foi acelerado a $41^{\circ} \mathrm{C}$ e $75 \%$ de UR, por 30 e 60 dias, e feijão novo mantido a $5^{\circ} \mathrm{C}$ e $60 \%$ de UR foi considerado controle. Foram avaliados o tempo de cozimento, por meio do equipamento de Mattson adaptado; a composição química e o pH dos grãos; a solubilidade em água e o perfil eletroforético das proteínas. Os resultados foram submetidos à análise de variância e teste de comparação de médias de Tukey (p<0,05). Verificou-se que o armazenamento, nos dois tempos, causou: aumento no tempo de cozimento dos grãos; diminuição do teor de umidade, aumento do teor de cinzas e manutenção dos teores de proteinas, lipídeos e carboidratos; diminuição do pH e diminuição da solubilidade e a mudança do perfil eletroforético das proteinas. Estes resultados estão de acordo com dados da literatura, que demonstram que durante o armazenamento de feijão em alta temperatura e umidade relativa há formação de ácidos, conduzindo à diminuição da solubilidade e estabilidade térmica das proteinas.

Palavras-chave: eletroforese; feijão-duro; Phaseolus vulgaris; pH; proteinas; solubilidade.
\end{abstract}

\section{SUMMARY}

PHYSICAL AND CHEMICAL PROPERTIES OF AGED DRY BLACK COMMON BEANS, IAPAR 44 CULTIVAR. Beans stored for long periods at high temperature and humidity become hardened and resistant to cook. This happens due to the development of the hard-to-cook defect. The objective of this work was evaluate some physical and chemical properties of the aged dry black common beans (Phaseolus vulgaris L.), Iapar 44 cultivar. The aging of beans was accelerated at $41^{\circ} \mathrm{C}$ and $75 \% \mathrm{RH}$, for 30 e 60 days; and new beans, kept at $5^{\circ} \mathrm{C}$ and $60 \% \mathrm{RH}$ was used as the control. The cooking time, determined by a Mattson-type cooker; the chemical composition and the $\mathrm{pH}$ of the grains; the water solubility and protein eletrophorectic profile were evaluated. The results were submitted to analyses of variance and mean comparison Tukey test $(\mathrm{p}<0.05)$. It was observed that the two storage periods, caused: increased time of cooking; decreased percentage of humidity, increased percentage of ash and maintained the percentages of protein, lipids and carbohydrates; decreased $\mathrm{pH}$ and decreased solubility and changed the protein eletrophorectic profile. These results are in accordance with the literature, which demonstrated that during aging of beans at high temperature and humidity there is acid formation, resulting in decreasing of solubility and thermal stability of protein.

Keywords: eletroforetic profile; hard-beans; Phaseolus vulgaris; pH; proteins; solubility.

\section{1 - INTRODUÇÃO}

Em países em desenvolvimento, os feijões são uma importante fonte de proteínas, calorias e outros nutrientes [18]. Entretanto, quando armazenados em condições de altas temperaturas e umidades relativas, comuns em países tropicais como o Brasil, eles se tornam endurecidos, ou seja, podem desenvolver o fenômeno conhecido como "hard-to-cook"(HTC) ou "dificil de cozinhar" [15].

O fenômeno HTC em grãos de leguminosas afeta sua qualidade e aceitabilidade. Com o endurecimento, aumenta o tempo de cocção dos grãos e, conseqüentemente, o gasto de energia, ocorrendo redução da palatabilidade e qualidade nutricional das leguminosas

\footnotetext{
Recebido para publicação em 16/03/2004. Aceito para publicação em 15/02/2005 (001311).

2. Departamento de Tecnologia de Alimentos e Medicamentos, Centro de Ciências Agrárias - Universidade Estadual de Londrina. Caixa Postal 6001, CEP: 86051-970, Londrina-PR - Brasil. E-mail: sandrah@uel.br

3. Departamento de Bioquimica, Centro de Ciências Exatas - Universidade Estadual de Londrina, Caixa Postal 6001, CEP: 86051-970, Londrina-PR - Brasil.

* A quem a correspondência deve ser enviada.
}

[18]. Feijões endurecidos não formam um caldo espesso e viscoso, sendo que este é um importante parâmetro de qualidade para os consumidores de feijão na América Latina. Portanto, feijões endurecidos são menos aceitos pelos consumidores e causam importantes perdas [4], assim é de grande importância tanto a prevenção do endurecimento como a utilização de grãos endurecidos [13].

Muitas hipóteses têm sido propostas para explicar a causa do endurecimento dos feijões, como: oxidação e/ou polimerização lipídica, formação de pectatos insolúveis, lignificação da lamela média, reação de $\beta$ eliminação da pectina, desnaturação protéica, ligações cruzadas de proteínas desnaturadas e/ou de polifenólicos e mecanismos múltiplos $[4,5,13,18]$.

LIU [13] apresentou um modelo de eventos múltiplos, no qual considera-se que o defeito HTC desenvolve durante o envelhecimento e maceração e manifesta no cozimento. Neste modelo, a formação de radicais livres, peroxidação lipídica, formação de ácidos, deterioração da membrana, desnaturação protéica, vazamento e redistribuição de íons estão associados ao envelhecimento e maceração, enquanto que a degradação e solubilização da pectina, coagulação protéica e gelatinização do amido ocorrem durante o cozimento. 
De acordo com LIU, MCWATTERS \& PHILLIPS [11] e com MARTÍN-CABREJAS et al. [14], o armazenamento de feijão-fradinho a $30^{\circ} \mathrm{C}$ e $64 \%$ de UR e de cinco variedades de feijão comum do Quênia a $30-40^{\circ} \mathrm{C}$ e $75 \%$ de UR conduziu à diminuição do $\mathrm{pH}$ do tecido dos grãos. Para LIU, MCWATTERS \& PHILLIPS [11] a diminuição do $\mathrm{pH}$ causou desnaturação protéica reversivel, que se refletiu na diminuição gradual da solubilidade em água e estabilidade térmica das proteínas, com aumento do tempo de armazenamento.

$\mathrm{O}$ armazenamento inadequado de feijões pode promover também alterações na composição química [3, 14] e no perfil eletroforético de proteínas [7].

Este trabalho teve como objetivo investigar o efeito das condições adversas de armazenamento do feijão sobre: 1) tempo de cozimento dos grãos, 2) composição química, 3) pH e solubilidade protéica em água, 4) perfil eletroforético das proteinas dos feijões e relacionar as mudanças ocorridas com o fenômeno HTC.

\section{2 - MATERIAL E MÉTODOS}

\section{1 - Matéria-prima}

O cultivar Iapar 44 de feijão comum (Phaseolus vulgaris L) preto, foi cultivado na região de Mafra - Santa Catarina.

\section{2 - Aceleração do envelhecimento dos grãos de feijão}

O feijão foi armazenado por 30 e 60 dias em duas estufas à temperatura de $41^{\circ} \mathrm{C}$ e $75 \%$ de umidade relativa para acelerar o envelhecimento dos grãos [9]. A umidade relativa de $75 \%$ foi obtida com um micro-clima de uma solução saturada de $\mathrm{NaCl}$ [17]. Ao término do tempo de armazenamento, as amostras permaneceram em temperatura e umidade ambientes durante 24 horas e então foram armazenadas em geladeira a $5^{\circ} \mathrm{C}$ e $60 \%$ de UR. Feijão novo armazenado a $5^{\circ} \mathrm{C}$ e $60 \%$ de UR foi utilizado como controle [2]. As amostras foram retiradas da geladeira 24 horas antes das análises.

\section{3 - Medida do tempo de cozimento}

Determinou-se o tempo de cozimento dos grãos, após maceração em água por 18 horas em temperatura ambiente, utilizando equipamento de MATTSON adaptado com 25 cilindros calibrados. O tempo de cozimento foi tomado quando 13 cilindros penetraram nos grãos [9].

\section{4 - Preparo das amostras}

Para as medidas da composição química, $\mathrm{pH}$, solubilidade protéica e eletroforese, os grãos crus de feijão foram triturados em moinho de facas marca Tecnal e o pó obtido foi classificado em malha de $0,59 \mathrm{~mm}$.

\section{5 - Composição química}

Os teores de umidade, proteínas, lipídeos e cinzas foram determinados, em triplicata, seguindo os méto- dos padrões descritos pela AOAC [1]. O teor de carboidratos foi estimado por diferença.

\section{6 - Determinação do pH dos grãos de feijão}

Um grama de amostra foi misturado em $50 \mathrm{~mL}$ de água destilada e homogeneizado por 2 minutos, e posteriormente verificado o $\mathrm{pH}$ em medidor de $\mathrm{pH}$ marca Alfhalab PA 200 [11].

\section{7 - Solubilidade das proteinas em água}

A solubilidade da proteína em água foi determinada de acordo com o método descrito por LIU, MCWATTERS \& PHILLIPS [11], com modificações. Um grama de amostra, foi misturado em $50 \mathrm{~mL}$ de água destilada, sob agitação. O material foi centrifugado a $5300 \mathrm{x} \mathrm{g}$, por 20 minutos, e o teor de proteína determinado no sobrenadante. Os valores de proteína total e no sobrenadante foram determinados pelo método de Kjeldahl [1], utilizando-se o fator de conversão 6,25. A solubilidade da proteína foi calculada como: (massa de proteína no sobrenadante / massa de proteína na amostra) x 100 .

\section{8 - Eletroforese}

O procedimento descrito por LAEMMLI [10] foi empregado para condução da eletroforese em SDS-PAGE. Foi utilizada uma cuba vertical (modelo 250-TA 75, marca PHARMACIA) e fonte com voltagem e corrente controladas (modelo EPS 3500, marca PHARMACIA).

Para a eletroforese foram preparados géis de $10 \mathrm{x}$ $6 \mathrm{~cm}$ utilizando-se poliacrilamida $12 \%$ (gel separador) e gel concentrador a 4\%. As amostras de feijão novo e armazenados foram solubilizadas no tampão da amostra, e $5 \mu \mathrm{L}$ da mistura contendo aproximadamente $40 \mu \mathrm{g}$ de proteínas foram aplicadas no gel. Um padrão de proteínas de peso molecular conhecido marca GIBCO BRL 10kD Protein Ladder, $\mathrm{n}^{\circ}$ 10064-012, contendo proteínas de massa molecular de 10 a $120 \mathrm{kD}$, com incrementos de 10 unidades e $200 \mathrm{kD}$, também foi aplicado ao gel. A corrente elétrica empregada foi de $50 \mathrm{~V}$ até as proteínas migrarem para o gel separador e então a corrente foi aumentada para $100 \mathrm{~V}$. A revelação das bandas protéicas foi feita através da coloração rápida com prata de acordo com o método apresentado por HENKESHOVEN \& DERNICK [6].

O peso molecular das frações protéicas foi determinado pela comparação da mobilidade eletroforética com o padrão de migração de proteínas padrão.

\section{9 - Análise estatística}

O experimento foi conduzido conforme um delineamento em blocos ao acaso. Os tratamentos foram os tempos de armazenamento ( 0 ou controle, 30 e 60 dias) e blocos as estufas. Os resultados foram submetidos à análise de variância, sendo as diferenças entre médias testadas pelo teste Tukey, a nivel de $5 \%$ de probabilidade. Foi utilizado o programa estatístico SAS [19]. 


\section{3 - RESULTADOS E DISCUSSÃO}

\section{1 - Medida do tempo de cozimento dos grãos}

$\mathrm{O}$ armazenamento dos feijões em alta temperatura e umidade relativa induziram o endurecimento dos grãos, causando um aumento de 2,3 e 6,4 vezes no tempo de cozimento dos feijões armazenados por 30 e 60 dias, respectivamente (Tabela 1). JACKSON \& VARRIANOMARSTON [9] verificaram que feijões pretos armazenados por 7 e 14 dias a $41{ }^{\circ} \mathrm{C}$ e $100 \%$ de UR tiveram seus tempos de cozimento aumentados em 1,16 e 1,48 vezes, respectivamente. DONADEL \& PRUDENCIOFERREIRA [3] após armazenamento de feijão, tipo carioca, a $41^{\circ} \mathrm{C}$ (sem controle da umidade relativa), verificaram aumentos de 5,61 e 6,25 vezes no tempo de cozimento quando os feijões foram armazenados por 30 e 40 dias. MORI [16], avaliando feijões armazenados a $40^{\circ} \mathrm{C}$ e $75 \%$ de UR por $10,20,30$ e 40 dias, observou aumentos na dureza, avaliada em Newton, dos grãos armazenados por 30 e 40 dias, de 1,66 para 1,74 e 1,60 para 1,98 vezes, em feijões preto e carioca, respectivamente. Estes resultados demonstram que ocorrem alterações na textura dos feijões à medida que aumenta o tempo de armazenamento em altas temperaturas e umidades relativas, resultando no defeito HTC, requerendo assim maiores tempos de cozimento.

TABELA 1. Medida do tempo de cozimento dos grãos de feijão comum controle e armazenados a $41^{\circ} \mathrm{C}$ e $75 \%$ de UR.

\begin{tabular}{cc}
\hline Tempo de armazenamento & Tempo de Cozimento (minutos) \\
\hline Controle $^{\star \star}$ & $21,83^{\mathrm{c}} \pm 0,75$ \\
30 dias & $50,33^{\mathrm{b}} \pm 3,08$ \\
60 dias & $139,50^{\mathrm{a}} \pm 8,98$
\end{tabular}

* Valores médios de duas repetições com três determinações cada uma \pm desvio padrão.

* Controle $=$ feijão novo armazenado a $5^{\circ} \mathrm{C}$ e $60 \%$ de UR

Médias acompanhadas por letras diferentes diferem significativamente $(p \leq 0,05)$

\section{2 - Composição química dos feijões}

A composição química do feijão novo e armazenados a $41^{\circ} \mathrm{C}$ e $75 \%$ de UR está apresentada na Tabela 2. Os grãos armazenados por 30 e 60 dias mostraram teores de umidade menores que os do controle. DONADEL \& PRUDENCIO-FERREIRA [3] também observaram diminuição no teor de umidade de farinha de feijões armazenados por 20, 30 e 40 dias.

Os teores de proteínas, lipídios e carboidratos se mantiveram com aumento do tempo de armazenamento. Entretanto, houve aumento significativo no teor de cinzas nos grãos armazenados por 30 e 60 dias, não havendo diferença entre estes dois tempos. Em relação ao teor de proteínas, resultado semelhante foi encontrado por MORI [16] que não observou diferença em farinhas de feijões tipo preto, cultivar Iapar 44 e tipo carioca, cultivar Iapar 81 armazenados por 10, 20, 30 e 40 dias a $40^{\circ} \mathrm{C}$ e 75 de \% UR. Já DONADEL \&
PRUDENCIO-FERREIRA [3] verificaram diminuição no teor de proteínas da farinha de feijão carioca armazenados a $41^{\circ} \mathrm{C}$, com aumento no tempo de armazenamento.

TABELA 2. Composição química dos grãos de feijão comum controle e armazenados a $41^{\circ} \mathrm{C}$ e $75 \%$ de UR*

\begin{tabular}{lccccc}
\hline \multicolumn{1}{c}{$\begin{array}{c}\text { Tempo de } \\
\text { armazenamento }\end{array}$} & $\begin{array}{c}\text { Umidade } \\
\text { \% }\end{array}$ & $\begin{array}{c}\text { Proteínas }^{\star \star \star} \\
\text { (b.s.)\% }\end{array}$ & $\begin{array}{c}\text { Lipídeos } \\
\text { (b.s.)\% }\end{array}$ & $\begin{array}{c}\text { Cinzas } \\
\text { (b.s.)\% }\end{array}$ & $\begin{array}{c}\text { Carboidra- } \\
\text { tos (b.s.)\% }\end{array}$ \\
\hline Controle $^{\star \star}$ & $13,55^{\mathrm{a}} \pm 0,11$ & $23,87^{\mathrm{a}} \pm 0,50$ & $2,51^{\mathrm{a}} \pm 0,42$ & $3,94^{\mathrm{b}} \pm 0,07$ & $69,69^{\mathrm{a}} \pm 0,89$ \\
30 dias & $12,76^{\mathrm{b}} \pm 0,79$ & $23,70^{\mathrm{a}} \pm 0,92$ & $2,31^{\mathrm{a}} \pm 0,62$ & $4,03^{\mathrm{a}} \pm 0,05$ & $69,97^{\mathrm{a}} \pm 0,79$ \\
60 dias & $12,80^{\mathrm{b}} \pm 0,12$ & $24,32^{\mathrm{a}} \pm 0,42$ & $2,81^{\mathrm{a}} \pm 0,60$ & $4,03^{\mathrm{a}} \pm 0,02$ & $69,18^{\mathrm{a}} \pm 0,60$
\end{tabular}

(b.s.) Base seca

* Valores médios de duas repetições com três determinações cada uma \pm desvio padrão.

** Controle $=$ feijão novo armazenado a $5^{\circ} \mathrm{C}$ e $60 \%$ de UR

$* * *$ Fator de conversão $=6,25$.

Médias na coluna acompanhadas por letras diferentes diferem significativamente $(\mathrm{p} \leq 0,05)$.

\section{3 - pH dos feijões e solubilidade das proteinas em água}

$\mathrm{O} \mathrm{pH}$ dos feijões controle e armazenados a $41^{\circ} \mathrm{C}$ e $75 \%$ de UR e a solubilidade das proteínas em água encontram-se na Tabela 3. Houve diminuição do $\mathrm{pH}$ dos grãos, estatisticamente significativa, após o armazenamento por 30 e 60 dias em relação ao controle. No entanto, os valores não atingiram a faixa ácida.

TABELA 3. Medida do $\mathrm{pH}$ e da solubilidade em água das proteínas de feijão comum controle e armazenados a $41^{\circ} \mathrm{C}$ e $75 \%$ de UR*.

\begin{tabular}{ccc}
\hline $\begin{array}{c}\text { Tempo de } \\
\text { armazenamento }\end{array}$ & $\mathrm{pH}$ & $\begin{array}{c}\text { Solubilidade } \\
\text { (g de proteína solúvel } / 100 \mathrm{~g} \\
\text { de proteína.) }\end{array}$ \\
\hline Controle $^{\star \star}$ & $6,47^{\mathrm{a}} \pm 0,09$ & $72,42^{\mathrm{a}} \pm 2,36$ \\
30 dias & $6,30^{\mathrm{b}} \pm 0,02$ & $67,61^{\mathrm{b}} \pm 2,61$ \\
60 dias & $6,23^{\mathrm{b}} \pm 0,10$ & $52,59^{\mathrm{c}} \pm 1,41$
\end{tabular}

* Valores médios de duas repetições com duas determinações cada uma \pm desvio padrão.

$*^{*}$ Controle $=$ feijão novo armazenado a $5^{\circ} \mathrm{C}$ e $60 \%$ de UR.

Médias na coluna acompanhadas por letras diferentes diferem significativamente $(\mathrm{p} \leq 0,05)$.

MORI [16] também encontrou diminuição no pH de feijões carioca, de 6,73 para 6,41; e preto, de 6,6 para 6,35 , armazenados a $40^{\circ} \mathrm{C}$ e $75 \%$ de UR por 40 dias. MARTÍN-CABREJAS et al.14] observaram diminuição do $\mathrm{pH}$ de feijões dos cultivares Mwitemania (de 6,30 para 5,86), Canadian Wonder (de 6,42 para 5,85), Mwezi Moja (de 6,41 para 6,02), Rose Coco (de 6,36 para 5,93) e Red Haricot (de 6,30 para 6,16) armazenados por cinco anos a $30-40^{\circ} \mathrm{C}$ e $75 \%$ de UR. LIU, MCWATTERS \& PHILLIPS [11] verificaram, em feijão fradinho, diminuição de $\mathrm{pH}$ de 6,76 para 6,35; 6,00 e 5,57 após 6, 12 e 18 meses de armazenamento a $30^{\circ} \mathrm{C}$ e $64 \%$ de UR.

Segundo LIU, MCWATTERS \& PHILLIPS [11], as condições inadequadas de armazenamento podem levar a acidificação do tecido conduzindo ao defeito de textura (HTC). LIU, PHILLIPS \& MCWATTERS [12] relata, em 
sua revisão, que o aumento de acidez no tecido do grão é uma alteração associada ao envelhecimento, sendo uma causa intermediária do defeito HTC. A acidificação do tecido pode ser devido à processos biológicos como a hidrólise enzimática (lipases) de lipídios em ácidos graxos, oxidação desses ácidos em ácidos orgânicos, hidrólise de proteínas pelas proteases com aumento de aminoácidos, hidrólise da fitina por ação da fitase formando fostato inorgânico e devido à ação de microrganismos. A formação de ácido pode ser iniciada pela presença de oxigênio que atua sobre os lipídios poliinsaturados das membranas celulares. Nesse processo, as cadeias hidrocarbônicas peroxidam (devido à presença de lipoxigenase, ou por ação não enzimática ou oxidativa) e formam radicais livres intermediários altamente reativos, os hidroperóxidos, que sofrem decomposição para produzir ácidos orgânicos, além de outros compostos [11, 13,14,18].

O armazenamento também provocou diminuição significativa na solubilidade das proteínas (Tabela 3). Resultados idênticos foram observados por HENTEGES, WEAVER \& NIELSEN [7], LIU, MCWATTERS \& PHILLIPS [11] e SOSULSKI, KASIRYE-ALEMU \& SUMNER [20].

LIU, MCWATTERS \& PHILLIPS [11] verificaram diminuição na solubilidade em água das proteínas de feijão-fradinho de $76,5 \%$ para $52 \%, 18 \%$ e $11,2 \%$ após 6 , 12 e 18 meses de armazenamento a $30^{\circ} \mathrm{C}$ e $64 \%$ de UR e atribuíram como causa provável da diminuição da solubilidade, o aumento de acidez ocorrido durante o armazenamento. Os valores de $\mathrm{pH}$ e solubilidade protéica encontrados no presente trabalho, para grãos controle e armazenados por 60 dias foram próximos aos observados pelos autores em grãos controle e armazenado durante 6 meses (180 dias) respectivamente.

LIU, MCWATTERS \& PHILLIPS [11] e MARTÍNCABREJAS et al. [14] sugeriram que o $\mathrm{pH}$ poderia ser um indicador conveniente do defeito HTC induzido por estocagem adversa em grãos, devido a observações consistentes entre a acidificação do tecido ocorrida durante a estocagem e a condução do defeito textural. Para LIU [13], nos grãos controle, o pH do tecido está próximo de 6,4 favorecendo a desnaturação protéica, a degradação por $\beta$ eliminação e dissolução da pectina durante o cozimento. Como resultado, as células se separam, os grânulos de amido se gelatinizam totalmente e os grãos se tornam macios. Em grãos envelhecidos, o pH diminui para faixa ácida $(5,5)$, causando a diminuição na solubilidade e estabilidade térmica das proteínas. Assim, a desnaturação das proteínas ocorre durante armazenamento e a coagulação predomina durante o cozimento, resultando em restrita gelatinização do amido. Também, neste meio ácido, a degradação por $\beta$ eliminação e solubilização da pectina são reduzidas durante o cozimento. Assim, os grãos se tornam dificeis de cozinhar [13, 14].

\section{4 - Eletroforese}

A Figura 1 representa o perfil eletroforético das frações protéicas do feijão controle e dos feijões armaze- nados. Após 30 e 60 dias de armazenamento as frações protéicas de pesos moleculares aproximados de 12,3 e $16,6 \mathrm{kD}$ (colunas 3 e 4) apresentaram bandas de menor intensidade que o controle (coluna 2), sendo que aos 30 dias (coluna 3) essa diminuição foi mais notável. Esses resultados foram confirmados após repetições da eletroforese, demonstrando que o armazenamento provocou alterações nas frações protéicas do feijão.

HUSSAIN, WATTS \& BUSHUK [8], observaram diferenças no perfil eletroforético de proteínas de feijão, armazenado por nove meses a $15^{\circ} \mathrm{C}$ e $35 \%$ de UR e do feijão armazenado a $30^{\circ} \mathrm{C}$ e $80 \%$ de UR, sendo que nesta condição houve o aparecimento de novas bandas de menor mobilidade, o que sugere, segundo o autor, que pode ter havido alguma associação e/ou desnaturação de proteínas durante o armazenamento.

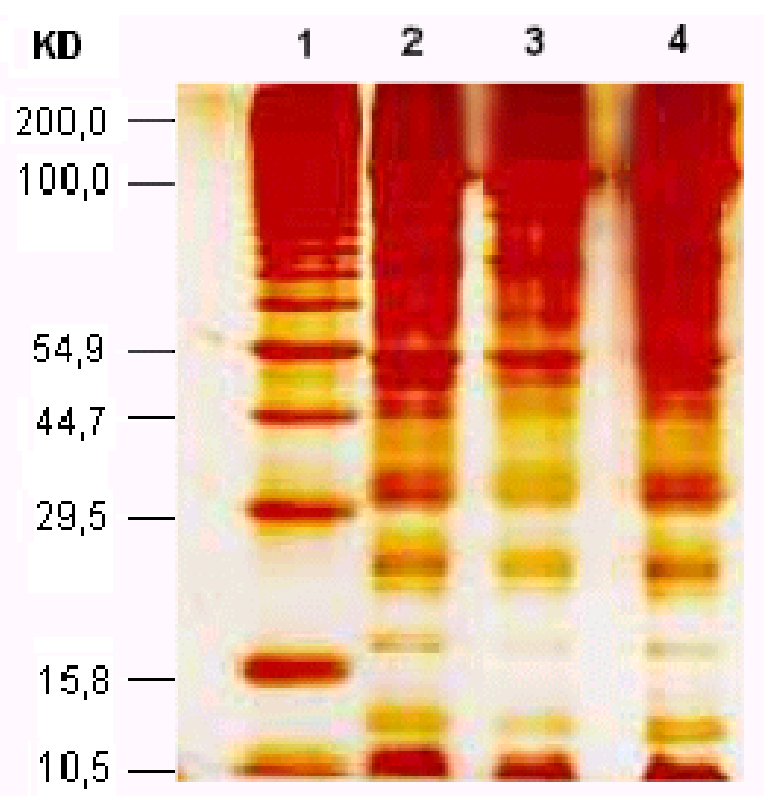

FIGURA 1. Eletroforese das frações protéicas dos grãos de feijão comum, controle e armazenados a $41^{\circ} \mathrm{C}$ e $75 \%$ de UR ( 1 = padrão de peso molecular; 2 = feijão controle; $3=$ feijão armazenado por 30 dias; 4 = feijão armazenado por 60 dias).

Por outro lado, BERRIOS, SWANSON \& CHEONG [2] não verificaram diferenças entre o perfil eletroforético de frações protéicas de feijão preto controle e de feijão armazenado por 2 anos a $4,5^{\circ} \mathrm{C}$ e $50-60 \%$ de UR e a $23-25^{\circ} \mathrm{C}$ e $30-50 \%$ de UR. Resultados semelhantes foram encontrados por MORI [16], que também não observou diferenças entre as bandas das frações protéicas de feijão carioca e preto, controle e armazenado por 40 dias extraído com tampão fosfato ou carbonato.

Apesar do $\mathrm{pH}$ do tecido dos grãos do feijão preto ter tido uma pequena diminuição e ter permanecido na faixa de neutralidade após 30 dias $(\mathrm{pH}$ 6,30) e 60 dias $(\mathrm{pH}$ $6,23)$ de armazenamento foi verificada diminuição significativa na solubilidade protéica e alterações no perfil eletroforético das proteínas indicando que outros mecanismos podem provocar essas alterações. 


\section{4 - CONCLUSÃo}

O armazenamento do feijão em condições de alta temperatura e umidade relativa provocou o desenvolvimento do fenômeno HTC, acarretando aumento do tempo de cozimento, alterações na composição química, e diminuição do $\mathrm{pH}$ dos grãos, diminuição da solubilidade e mudanças no perfil eletroforético das proteínas.

\section{5 - REFERÊNCIAS BIBLIOGRÁFICAS}

[1] ASSOCIATION OF OFFICIAL ANALYTICAL CHEMISTS AOAC. Official Methods of Analysis, $15^{\text {th }}$ ed. Washington, D. C., 1990.

[2] BERRIOS, J. D. J.; SWANSON, B. G.; CHEONG, W. A. Physico-chemical characterization of stored black beans (Phaseolus vulgaris L.). Food Res. Intern1., v. 32, p. 669-676, 1999.

[3] DONADEL, M. E.; PRUDENCIO-FERREIRA, S. H. Propriedades funcionais de concentrado protéico de feijão envelhecido. Ciênc. Tecnol. Aliment., v.19, n.3, p. 380-386, 1999.

[4] GARCIA, E; LAJOLO, F. M. Starch alterations in hardto-cook beans (Phaseolus vulgaris). J. Agric. Food Chem., v. 42, p. 612-615, 1994.

[5] GARCIA, E; FILISETTI, T.M.C.C.; UDAETA,J.E.M.; LAJOLO, J.M. Hard-to-cook beans (Phaseolus vulgaris): involvement of phenolic compounds and pectates. $\mathbf{J}$. Agric. Food Chem., v. 46, p. 2110-2116, 1998.

[6] HENKESHOVEN, J.; DERNICK, R. Simplied method for silver staining of proteins in polyacrilamide gels and the mechanism of silver staining. Eletroforesis, n. 6 , p. 103-112, 1985.

[7] HENTGES, D.L.; WEAVER, C.M.; NIELSEN, S.S. Changes of selected physical and chemical components in the development of the hard-to-cook bean defect. J. Food Sci., v. 56, n. 2, p. 436-442, 1991.

[8] HUSSAIN, A.; WATTS, B. M.; BUSHUK, W. Hard-to-cook phenomenon in beans: changes in protein eletrophoretic patterns during storage. J. Food Sci., v. 54, n. 5, p. 1367-1380, 1989.

[9] JACKSON, G. M.; VARRIANO-MARSTON, E. M. Hard-tocook phenomenon in beans: effects of accelerated storage on water absorption and cooking time. J. Food Sci., v. 46, n. 3, p. 799-803, 1981.

[10] LAEMMLI, U. K. Cleavage of structural proteins during the assembly of the head of bacteriophage T 4. Nature, n. 227, p. 680-685, 1970.

[11] LIU, K.; MCWATTERS, K. H.; PHILliPS, R. D. Protein insolubilization and termal destabilization during storage as related to hard-to-cook defect in cowpeas. J. Agric. Food Chem., v. 40, p. 2483-2487, 1992.

[12] LiU, K.; PHILliPS, R. D.; MCWATTERS, K. H.;. Mechanism of pectin change during soaking and cooking as related to hard-to-cook defect in cowpeas. J. Agric. Food Chem., v. 41, n. 9, p. 1476, 1993.

[13] LIU, K. Cellular, biological, and physicochemical basis for the hard-to-cook defect in legume seeds. Crit. Rev. Food Sci. Nutr., v. 35, n. 4, p. 263-298, 1995.

[14] MARTÍN-CABREJAS, M. A., ESTEBAN, R. M.; PEREZ, P.; MAINA, G.; WALDRON, K. W. Changes in physicochemical properties of dry beans (Phaseolus vulgaris L.) during long-term storage. J. Agric. Food Chem., v. 45, p. 3223-3227, 1997.

[15] MARTÍN-CABREJAS, M. A.; JAIME, L.; KARANJA, C.; DOWNIE, A. J.; PARKER, M. L.; LOPEZ-ANDREU, J.; MAINA, G.; ESTEBAN, R. M.; SMITH, A. C.; WALDRON, K. W. Modifications to physicochemical and nutritional properties of hard-to cook (Phaseolus vulgaris L.) by extrusion cooking. J. Agric. Food Chem., v. 47, p. 1174-1182, 1999.

[16] MORI, A. L. B. Solubilidade das proteinas de feijão comum envelhecido. Londrina, 2001, 78 p. Dissertação (Mestre em Ciência de Alimentos), Universidade Estadual de Londrina (UEL).

[17] RAO, M. A.; RIZVI, S. S. H. Engeneering properties of foods. New York: Marcel Dekker, Inc., 398 p, 1986.

[18] REYES-MORENO, C.; PAREDES-LÓPEZ, O. Hard-tocook phenomenon in common beans - A review. Crit. Rev. Food Sci. Nutr., v. 33, n. 3, p. 227-286, 1993.

[19] SAS - Institute. SAS User's Guide: statistic. Cary, USA INST., 1995.

[20] SOSULSKI, F. W.; KASIRYE-ALEMU, E. N.; SUMNER, A. K. Microscopic, nutritional and functional properties of cowpea flours and concentrates during storage. J. Food Sci., v. 52, p. 700-706, 1987. 